\title{
'IDDAH DAN IHDAD BAGI WANITA KARIR
}

\author{
Edi Susilo \\ Pascasarjana UIN Sunan Ampel Surabaya. \\ E-mail: edisusilo@gmail.com
}

\begin{abstract}
The concept of iddah and ihdad in Islamic jurisprudence that has been running so far requires women to shy away from the social interaction and the avoidance of activities that may attract the attention of men, such as preening, ornate, and so on. They are regarded to mediate the appearance of the probibited wedding on the waiting period ('iddah). It is very collide with the present fact about the career women which demand them to work hard, always look attractive, and keep the interaction with the opposite sex. These factors encourage them to have an outdoor activity to support their financial result and career. The clash between the concept of fiqh and the current condition of the career women becomes the object of the discussion. Consideration that can change the legal status of 'iddah and ibdad when collides with the issue of career women is a consideration hajah and darurah. In addition, the legal settlement of the career women can be said to be more applicable, effective, and humane. This paper will examine about iddah and ibdad for the career women through the lens of maqasid al-shari'ah so the concept of Islamic jurisprudence can still be applied in contemporary era without negating the rights of the individual and social.
\end{abstract}

Abstrak: Konsep iddah dan ibdad dalam fiqh yang telah dijalankan selama ini, mengharuskan wanita untuk menghindar dari interaksi sosial serta menghindar dari aktifitas yang dapat menarik perhatian laki-laki, semisal bersolek, berhias, dan sebagainya karena dianggap dapat menjadi perantara munculnya pernikahan pada masa iddab yang hukumnya dilarang. Hal ini sangat berbenturan dengan fakta kekinian tentang wanita karir yang menuntut wanita bekerja ekstra untuk memenuhi kebutuhan hidup yang mengharuskan wanita ini untuk selalu berpenampilan menarik serta menjaga interaksi dengan siapapun termasuk lawan jenis sehingga tertuntut untuk selalu beraktifitas keluar rumah, hal ini ditujukan untuk menunjang hasil finansial dan karirnya. Dua fakta mengenai benturan konsep fiqh dengan kondisi kekinian yang dalam hal ini adalah wanita karir, menjadi objek pembahasan yang menarik untuk kemudian dicarikan solusinya. Pertimbangan yang dapat merubah hukum 'iddah dan ibdad ketika berbenturan dengan masalah wanita karir adalah pertimbangan hajat dan $\mathrm{d}$ \}arurat mengingat efektifitas hajat dan $\mathrm{d}$ \}arurat sehingga penyelesaian hukum 'iddah dan ihdad bagi wanita karir dapat dikatakan lebih aplikatif, efektif dan humanis untuk era kekinian dengan pertimbangan hajat dan darurat. Tulisan ini akan mengkaji tentang Iddah dan Ibdad Bagi Wanita Karir melalui kacamata maqasid ash-Shariah sehingga konsep fiqh masih dapat

The Indonesian Journal of Islamic Family Law

Volume 06, Nomor 02, Desember 2016; ISSN:2089-7480 
diaplikasikan di era kekinian tanpa meniadakan hak-hak individu dan sosial.

Kata Kunci: Iddah, Ibdad, Wanita Karir

\section{Pendahuluan}

Masyarakat Arab pra-Islam telah melaksanakan praktik hukum yang dikenal dengan iddah dan ibdad (atau bidad). Praktisnya, kaum perempuan yang baru saja ditinggal mati oleh suaminya bahkan juga oleh anggota keluarganya yang lain, harus mengisolasi diri di dalam ruang terpisah selama setahun penuh. Dalam masa pengasingan itu, perempuan tersebut tidak diperkenankan untuk memakai wewangian, memotong kuku, menyisir rambut, dan berganti pakaian. Dia akan diberi seekor binatang seperti keledai, kambing atau burung untuk dipakai menggosok-gosok kulitnya. Diilustrasikan dalam sebuah hadits, begitu busuknya bau badan perempuan yang ber-ibdad tersebut, sehingga tidak seorang pun berani menghampirinya. Seandainya ia keluar ruangan, dengan segera burung gagak akan menyergap karena bau busuk yang ditimbulkan. ${ }^{2}$

Islam datang untuk mengatur secara adil praktik tersebut dengan penetapan dan pengurangan masa 'iddah dan ibdad yang telah dijalankan sejak masa tashri'. Namun ketika zaman telah berkembang yang berakibat pada perbedaan kondisi sosial masyarakat antara masa tashri', masa doktrin fuqaha' klasik, dengan masa sekarang, di samping kecanggihan teknologi telah membuka cakrawala baru, mendorong adanya koreksi serta perumusan konsepsi fiqh yang aplikatif, adaptif, dan humanis untuk masa sekarang.

Iddah dan ibdad dalam praktiknya, mengharuskan wanita menghindar dari interaksi sosial serta dari aktifitas yang dapat menarik perhatian laki-laki, semisal bersolek, berhias, dan sebagainya karena dianggap dapat menjadi perantara munculnya pernikahan pada masa iddah yang hukumnya dilarang. Hal ini sangat berbenturan dengan fakta kekinian tentang wanita karir

${ }^{1}$ Syah Waliyullah ad-Dihlawiy, Hujjah Allah al-Balighah, (Beirut: Dar Ihya` alUlum, tt.), Jilid II, 377.

${ }^{2}$ Muhammad bin Idris al-Shafi'i, Al-Um, (Maktabah Shamelah), jilid V, 230. 
yang menuntut wanita bekerja ekstra untuk memenuhi kebutuhan hidup. Tuntutan ini mengharuskan wanita selalu berpenampilan menarik serta menjaga interaksi dengan siapapun, termasuk lawan jenis serta harus beraktifitas di luar rumah untuk menunjang finansial dan karirnya.

Dua fakta mengenai benturan konsep fiqh klasik dengan kondisi kekinian, yang dalam hal ini adalah wanita karir, menjadi objek pembahasan menarik untuk dicarikan solusinya melalui kacamata maqasid ash-Shariah sehingga konsep fiqh masih dapat diaplikasikan di era kekinian tanpa meniadakan hak-hak individu dan sosial.

\section{Emansipasi Wanita dan Wanita Karir}

Diakui atau tidak, dehumanisasi terhadap kaum perempuan pernah terjadi dalam panggung sejarah akibat budaya patriarkhi, bahkan hingga sekarang masih terlihat diskriminasi terhadap perempuan. Menurut penulis, berdasarkan penelusuran literatur, faktor materialistik merupakan faktor utama dan dasar yang menjadi penyebab terciptanya dehumanisasi terhadap perempuan yang kemudian berimplikasi pada pembentukan budaya patriarkhi di segala sektor kehidupan.

Pada zaman batu, ketika tanah masih menjadi milik bersama semua kalangan, belum sempurnanya sekop dan cangkul membatasi kemungkinan adanya pertanian yang layak sehingga kekuatan perempuan lebih cocok untuk berkebun dan melakukan pekerjaan yang produktif berupa membuat barang-barang dari tanah liat, menenun serta membereskan urusan rumah tangga. Sedangkan laki-laki bekerja mencari ikan dan berburu. Sebuah pembagian tugas yang menunjukan peran penting wanita dalam sektor ekonomi produktif. ${ }^{3}$ Namun setelah penemuan tembaga, timah, perunggu dan besi yang dapat dijadikan sebagai alat-alat baru, maka sebuah kekalahan sejarah bagi wanita yang perannya tergantikan oleh alat-alat tersebut. Di sisi lain, efisiensi dan intensitas pekerjaan untuk membersihkan hutan diperlukan tenaga laki-laki, maka laki-laki juga membutuhkan tenaga perempuan

${ }^{3}$ Ibid., 76. 
dengan jalan perbudakan sehingga menggeser peran produktifitas perempuan. Otoritas dan peran produktif laki-laki inilah yang menjadikan wanita dianggap remeh, bahkan berakibat pada hak kepemilikan harta diwariskan dari ayah ke anak laki-laki, bukan pada ibu atau anak perempuan. ${ }^{4} \mathrm{Hal}$ ini juga dibenarkan dalam fakta sejarah Mekah pra Islam di mana ideologi masyarakat Mekah memandang lemah perempuan dalam proses produksi. ${ }^{5}$ Pergeseran otoritas produktif perempuan ini berdasarkan faktor materialistik kemudian menciptakan budaya patriarkhi dengan dominasi laki-laki dalam sektor kehidupan.

Namun lambat laun, ketika wanita sudah mulai mampu bekerja dan bersaing dengan laki-laki, otoritas produktif wanita melalui perjuangan bertajuk emansipasi wanita, gender, dan sejenisnya pada abad ke-20, kini telah menampakkan hasil. Dalam sektor politik, budaya, ekonomi, olah raga, dan lain sebagainya, wanita telah terlibat aktif. Misalnya sektor politik, Benazir Bhutto pernah menjadi Perdana menteri Pakistan yang sebelumnya dikuasai oleh perdana menteri Ziya'ul Khaq, Begum Khalida Zia (Perdana Menteri Bangladesh), Megawati Soekarno Putri (Presiden Indonesia), dll. Di sektor ekonomi banyak wanita yang bekerja bahkan sebagai TKW di luar negeri, pramugari, dll.

Mengenai istilah wanita, dalam kamus besar bahasa Indonesia berarti perempuan dewasa. . Sedangkan kata "karir" berarti pengembangan dan kemajuan dalam kehidupan, pekerjaan, jabatan dan sebagainya. Karir dapat juga berarti pekerjaan yang memberikan harapan untuk maju. ${ }^{7}$ Dengan demikian, wanita karir adalah wanita yang bekerja untuk memenuhi kebutuhan hidup pribadi dan keluarga yang lebih maju secara finasial dan jabatan melalui peningkatan karir dan pekerjaan. Hal ini berakibat pada kebutuhan interaksi dengan semua jenis kelamin dan aktifitas di

${ }^{4}$ Ibid.

${ }^{5}$ A. M. Sahal Mahfudz dalam Pengantar Husein Muhammad, Figh Perempuan Refleksi Kiai atas Wacana Agama dan Gender, (Yogyakarta: Lkis, 2009), xiii.

${ }^{6}$ Anton M. Moeliono (Penyunting Penyelia), Kamus Besar Bahasa Indonesia, (Jakarta: Departemen Pendidikan dan Kebudayaan RI, 1989), Cetakan II, 1007.

${ }^{7}$ Ibid. 
luar rumah serta keniscayaan berhias diri dalam menunjang karir dan pekerjaan.

\section{'Iddah Perspektif Fiqh Salaf}

Kata 'iddah merupakan derivasi kata al-'adad yang berasal dari kata kerja "adda-ya'uddu" yang artinya kurang lebih (hitungan, perhitungan atau sesuatu yang dihitung). ${ }^{8}$ Penggunaan kata ini dalam fiqh karena makna kata ini mengandung arti hitungan atau bilangan suci atau haid.' Sedangkan definisi shara' terdapat beberapa redaksi yang berbeda-beda. Menurut ulama' Shafi'iyyah: "Masa penantian yang digunakan wanita (janda) untuk mengetahui kosongnya rabim, pengabdian pada Allah dan bela sungkawa atas kematian suami." Sedangkan Menurut ulama' Hanafiyyah: 'Penantian yang wajib dilakukan wanita (janda) ketika putusnya perkawinan atau sejenisnya" "Menurut ulama' Hanaflyyah yang lain: "Nama bagi sebuah masa yang dipakai untuk menghabiskan sesuatu yang masib tersisa akibat dari pernikahan". ${ }^{12}$ Menurut ulama' Malikiyyah yang diungkapkan Ibn ar-Rifah: "Masa yang mencegah pernikahan karena rusaknya pernikahan, matinya suami atau talaknya suami",13

\section{Macam dan Hukum 'Iddah}

Wanita yang putus perkawinannya menurut Ibnu Rushd dikategorikan dalam beberapa penggolongan:

1. Wanita yang pada saat putus perkawinannya masih belum pernah berhubungan badan dengan suami. Menurut Ibnu Rushd,

${ }^{8}$ Zayn al-Din Ibnu Nujaym al-Hanafi, al-Bahr al-Raiq Sharh Kanzu al-Daqaiq, (Maktabah Shamelah Vol. VI), jilid IV, 138., Wahbah az-Zuhaily, al-Figh alIslamiy Wa Adillatubu, (Damaskus: Dar al-Fikr, 1996), Jilid VII, 624.

'Zayn al-Din al-Malibari, Fath al-Mu'in, (Beirut: Dar al-Fikr, tt.), 37

10 Ibid., dan Abu Yahya Zakariya al-Ansari, Fath al-Wabab bi Sharh Manhaj alTullab, (Beirut: Dar al-Kutub al-'Alamiyyah, tt.), jilid II, 179.

${ }^{11 Z}$ Zayn al-Din Ibnu Nujaym al-Hanafi, al-Babr, jilid IV, 138.

${ }^{12}$ 'Ala'uddin al-Kasani, Bada'i' al-Shana'I fi Tartibi al-Shara'i', (Maktabah Shamelah Vol. VI), jilid III, 190.

${ }^{13}$ Ahmad bin Ghanim bin Salim al-Nafrawi, al-Fawakih al-Diwani 'ala Risalati Ibn Abi Zayd al-Qayrawani, (Maktabah Shamelah Vol. VI), jilid. III, 1054. 
ijma' menyatakan tidak berlakunya 'iddab bagi wanita ini. ${ }^{14}$ Berdasarkan firman Allah surat Al-Ahzab ayat 49 yang artinya :

"Hai orang-orang yang beriman, apabila kamu menikabi perempuanperempuan yang beriman, kemudian kamu ceraikan mereka sebelum kamu mencampurinya Maka sekali-sekali tidak wajib atas mereka 'iddah bagimu yang kamu minta menyempurnakannya. Maka berilah mereka mut'ah dan lepaskanlah mereka itu dengan cara yang sebaikbaiknya."

2. Wanita yang pada saat putus perkawinannya telah melakukan hubungan badan dengan suami. Bagi wanita golongan ini berlaku hukum 'iddah. ${ }^{15}$ Tddah bagi wanita ini ada tiga bentuk:

a. Iddah dengan quru'. 'Iddah jenis ini berlaku bagi wanita normal yang kebiasaannya mengeluarkan darah haid. Ulama' sepakat bahwa 'iddah wanita ini adalah tiga quru'. 'Hal ini didasarkan pada firman Allah dalam surat al-Baqarah (1) ayat 228: "wanita-wanita yang ditalak handaklah menahan diri (menunggu) tiga kali quru'..."

b. 'Iddah dengan ashbur (bulan). 'Iddah jenis ini berlaku bagi wanita yang ditinggal mati suaminya baik telah disetubuhi atau belum, baik tergolong wanita yang biasa haid atau bukan. ${ }^{17} \mathrm{Hal}$ ini didasarkan pada firman Allah dalam surat alBaqarah ayat 234 yang artinya:

"orang-orang yang meninggal dunia di antaramu dengan meninggalkan isteri-isteri (bendaklah Para isteri itu) menanggubkan dirinya (beriddah) empat bulan sepuluh hari. kemudian apabila telah habis iddahnya, Maka tiada dosa bagimu (para wali) membiarkan mereka berbuat terhadap diri mereka menurut yang patut. Allah mengetahui apa yang kamu perbuat"

${ }^{14}$ Ibnu Rushd, Bidayat al-Mujtabid Wa Nihayat al-Muqtasid, (Beirut: Dar al-Fikr, 1998), Jilid II, 66.

${ }^{15}$ Ibid., 66.

${ }^{16}$ Wahbah az-Zuhaily, al-Figh, Jilid IX, hal.595. dan Ibnu Rushd, Bidayat, Jilid II, 67, dan Ali al-Sabuni, Rawa'I al-Bayan fi Tafsiri aayat al-Ahkam, (Beirut: Dar alFikr, tt.), jilid I, 256.

${ }^{17}$ Wahbah az-Zuhaily, al-Fiqh al-Islamiy, Jilid IX, 597. 
Alasan hukum diwajibkannya 'iddah jenis ini adalah agar memperlihatkan kesedihan karena putusnya nikmat pernikahan. ${ }^{18}$ Selain wanita yang ditinggal mati suaminya, wanita menoupouse dan wanita kecil yang belum haid, iddah-nya sebanyak 3 bulan. ${ }^{19}$ Sesuai dengan surat al-Talaq ayat 4 yang artinya:

"dan perempuan-perempuan yang tidak baid lagi (monopause) di antara perempuan-perempuanmu jika kamu ragu-ragu (tentang masa iddahnya), Maka masa 'iddah mereka adalah tiga bulan; dan begitu (pula) perempuan-perempuan yang tidak haid. dan perempuanperempuan yang hamil, waktu iddah mereka itu ialah sampai mereka melabirkan kandungannya. dan barang -siapa yang bertakwa kepada Allah, niscaya Allab menjadikan baginya kemudahan dalam urusannya".

c. 'iddah dengan melahirkan.

Iddah jenis ini berlaku bagi wanita yang ketika ditalak dalam keadaan hamil. Hal ini sesuai dengan firman Allah Swt. surat al-Talak ayat 4 yang artinya:

"dan perempuan-perempuan yang hamil, waktu 'iddah mereka itu ialah sampai mereka melabirkan kandungannya. dan barang -siapa yang bertakwa kepada Allah, niscaya Allah menjadikan baginya kemudahan dalam urusannya".

Iddah wanita hamil sampai wanita itu melahirkan, hal ini juga sesuai dengan alasan bahwa 'iddah dishariatkan untuk mengetahui isi rahim wanita, dan melahirkan merupakan pertanda bahwa isi rahim telah keluar. Bahkan jika antara talak dengan masa kelahiran terbilang singkat, ‘ddah-nya tetap dianggap sah. ${ }^{20}$

\section{Konsekuensi iddah}

Wanita yang ditalak atau ditinggal mati suaminya dikenai khitab hukum 'iddah, yakni:

1. Larangan di-khitbah atau dilamar. Sesuai surat al-Baqarah ayat 235 yang artinya:

${ }^{18}$ Ibid.

${ }^{19}$ Ibid.

${ }^{20}$ Ibid., Jilid IX, 598. 
"dan tidak ada dosa bagi kamu meminang wanita-wanita itu[148] dengan sindiran atau kamu Menyembunyikan (keinginan mengawini mereka) dalam batimu. Allab mengetabui bahwa kamu akan menyebutnyebut mereka, dalam pada itu janganlah kamu Mengadakan janji kawin dengan mereka secara rahasia, kecuali sekedar mengucapkan (kepada mereka) Perkataan yang ma'ruf."

Hal ini dilarang karena dapat membangkitkan permusuhan dengan suami (atau keluarga suami) yang awal. ${ }^{21}$

2. Larangan menikah atau dinikahi. Sesuai surat al-Baqarah ayat 235 yang artinya:

"dan janganlah kamu ber'azam (bertetap hati) untuk beraqad nikah, sebelum habis iddabnya. dan ketabuilab bahwasanya Allab mengetabui apa yang ada dalam hatimu; Maka takutlah kepada-Nya, dan ketabuilah bahwa Allah Maha Pengampun lagi Maha Penyantun."

Hal ini dilarang karena wanita yang 'iddab talak raj'i masih memiliki hak rujuk pada wanita itu. ${ }^{22}$ Selain itu tujuan wanita iddab talak ba'in atau wafat juga menghindari kekacauan nasab.

3. Larangan keluar rumah

Menurut Ulama' Hanafiyyah, wanita 'iddah karena talak haram untuk keluar rumah baik siang maupun malam. ${ }^{23} \mathrm{Hal}$ ini didasarkan pada surat al-Talaq ayat 1 yang arrtinya:

"janganlah kamu keluarkan mereka dari rumah mereka dan janganlah mereka (diizinkan) ke luar kecuali mereka mengerjakan perbuatan keji yang terang"

Selain ini, surat al-Talaq ayat 6 menyatakan bahwa:

"tempatkanlab mereka (para isteri) di mana kamu bertempat tinggal menurut kemampuanmu dan janganlah kamu menyusabkan mereka untuk menyempitkan (hati) mereka."

Perintah ayat untuk menempatkan wanita di rumah berarti larangan untuk mengeluarkan atau mengajak keluar wanita itu. ${ }^{24}$

${ }^{21}$ Wahbah az-Zuhaily, al-Figh al-Islamiy, Jilid IX, 617.

22Ibid.

${ }^{23}$ Ibid., Jilid IX, hal. 618.

${ }^{24}$ Ibid. 
Dengan demikian, wanita yang ditalak ataupun ditinggal mati suami diharuskan melakukan iddah dengan konsekwensi larangan menerima pinangan, melakukan pernikahan baru, dan keluar rumah.

\section{Ihdad Perspektif Fiqh Salaf Definisi Ihdad}

Ihdad merupakan derivasi dari dua kata, yakni ahadda-yubidduibdad dan hadda-yubiddu-bidad yang artinya mencegah (al-man'u). ${ }^{25}$ Keduanya juga sama bermakna meninggalkan berhias diri. ${ }^{26}$ Adapun pengertian perspektif shara': Menurut Abu 'Umar Yusuf al-Namri al-Qurtubi, ulama' Madhhab Malikiyyah dengan mengutip pendapat Imam Maliki, ibdad adalah "Menjaubi segala sesuatu yang digunakan untuk berbias bagi wanita". Menurut Zayn alDin Ibnu Nujaym ulama' Madhhab Hanafiyyah: ${ }^{27}$ Ibdad berarti "Meninggalkan berbias (perbiasan) dan sejenisnya yang dilakukan oleh wanita dalam masa "iddah talak bain atau 'iddah kematian suami."

${ }^{28}$ Terdapat rumusan definisi lain dari Abu Hasan al-Mawardi, salah satu ulama' Madhhab Shafi'iyyah: Ibdad adalah "Mencegah berbias dari pakaian ataupun selain pakaian ketika berbias berakibat membangkitkan gairah para laki-laki kepadanya ${ }^{29}$

Dari berbagai definisi yang ada, pada dasarnya tidak ada perbedaan pada definisi ibdad, yakni perbuatan wanita yang menjalani masa iddah dengan menanggalkan perhiasan untuk menghindari mubasharah (interaksi) dengan lelaki yang berkemungkinan akan menjalin hubungan peminangan (khitbah) dan pernikahan. Jika ditelusuri lebih lanjut, ihdad merupakan tindakan prefentif agar tidak ada lelaki yang melamarnya, agar terhindar dari perbuatan nista (zina), agar wanita itu juga terhindar dari tergesa-gesa menikah kembali karena ia masih dalam keadaan

${ }^{25}$ Muhammad al-Khatib al-Sharbini, al-Iqna' fi Hilli Alfadz, Abi Shuja', (Maktabah Shamelah), jilid II, 471.

${ }^{26}$ Zayn al-Din Ibnu Nujaym al-Hanafi, al-Babr al-Raiq, jilid IV, 163.

${ }^{27} \mathrm{Abu}$ Umar Yusuf al-Namri al-Qurtubi, Al-Kafi fi Fiqh Abli al-Madinah, (Riyadl: Maktabah Riyadl al-Hadithah, 1980), jilid II, 622-623.

${ }^{28}$ Zayn al-Din Ibnu Nujaym al-Hanafi, al-Babr al-Raiq, jilid IV, 163.

${ }^{29}$ Abu Hasan al-Mawardi, Al-Hawi al-Kabir, (Maktabah Shamelah), jilid. 11, 614. 
'iddah (berkabung). Kesemua tindakan pencegahan tersebut merupakan tindakan yang tergolong shad al-dzari'ah.

\section{Hukum dan Macam-Macam Ihdad}

Beberapa macam ibdad dilihat dari bentuk putusnya perkawinan pelaku ibdad (wanita):

1. Istri yang ditinggal mati suaminya.

Istri yang ditinggal mati suaminya menurut Ulama' $\mathrm{H}$ \}anabilah, ${ }^{30}$ Malikiyyah, ${ }^{31}$ Shafi'iyyah, ${ }^{32}$ dan Hanafiyah $^{33}$ hukumnya wajib. Oleh sebab itu hukum ihdad ini tergolong ijma'. Sekalipun Imam Abu hasan al-Bashri dan Imam al-Shu'abi menyatakan tidak wajib dan pendapat ini tergolong pendapat langka (shad $)$ ), bahkan oleh Ibnu Qudamah dianggap menyalahi sunnah (kbilaf al-sunnab). ${ }^{34}$ Argumentasi kedua ulama' tersebut: Berdasar hadith:

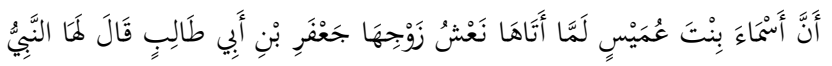

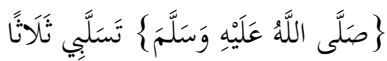

Hadith ini menunjukan bahwa masa ibdad hanyalah tiga hari. Selain itu hukumnya tidak wajib. ${ }^{35}$

Serta berdasar hadith:

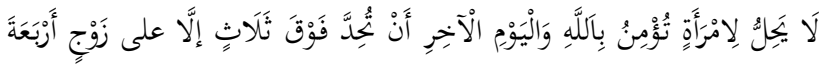

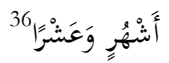

Pada dasarnya tidak petunjuk dalil tentang kewajiban ibdad dalam hadith ini, karena pengecualian (istithna) yang jatuh setelah peniadaan (nafi) menunjukan ketetapan hukum boleh, bukan wajib. ${ }^{37}$

Adapun argumentasi yang dibangun, menurut Imam Shafi'i bahwa hukum ibdad tidak tertulis dalam al-Qur'an, namun

\footnotetext{
${ }^{30}$ Abdullah bin Ahmad Ibnu Qudamah, al-Mughni, jilid IX, 167.

${ }^{31} \mathrm{Abu}$ Umar Yusuf al-Namri al-Qurtubi, Al-Kafi, jilid II, 622.

32Sharaf al-Din al-Nawawi, Al-Majmu', jilid 18, 181.

${ }^{33}$ Zayn al-Din Ibnu Nujaym al-Hanafi, al-Bahr al-Raiq, jilid IV, 163.

${ }^{34}$ Abdullah bin Ahmad Ibnu Qudamah, al-Mughni, jilid IX, 167.

${ }^{35} \mathrm{Abu}$ Hasan al-Mawardi, Al-Hawi, jilid. 11, 615.

${ }^{36}$ Zayn al-Din Ibnu Nujaym al-Hanafi, al-Babr al-Raiq, jilid IV, 163.

${ }^{37}$ Ibid.
} 
ketika Rasulullah saw. memerintahkan wanita untuk ber-ibdad maka hukum tersebut sama dengan kewajiban dan ketetapan alQur'an. $^{38}$

2. Istri yang ditalaq $b a^{\prime} i n$

Istri yang ditalaq ba'in menurut ulama' Hanafiyyah dan Sufyan al-Thauri ibdad-nya wajib, sedangkan menurut Imam Shafi'i menganggap tidak wajib tapi diniliai bagus (istibsan) jika dilaksanakan. ${ }^{39}$ Penggunaan istilah istibsan Imam Shafi'i, didengungkan oleh Ibnu Rushd. Namun jika ditelusuri dalam kitab al-Um, Imam Shafi'i ternyata tidak menggunakan istilah istibsan. ${ }^{40}$

Sedangkan menurut Madhhab Malikiyah, istri yang ditalak, baik talak ba'in ataupun raj'iy tidak wajib ibdad. ${ }^{41}$ Dalil yang digunakan adalah athar dari Ibnu Wahab dari Yunus yang bertanya pada Rabi'ah, "apakah wanita yang ditalak wajib menjahui perbiasan?" Maka jawabnya, "tidak ada yang harus dijaubi". Selain dari athar tersebut, terdapat sanad lain yang senada bersumber dari Ibnu Wahab, dari beberapa gurunya (ahli ilmu) dari Abdullah bin Umar, Abi Zubad dan 'Ata' bin Abi Rabah. ${ }^{42}$

3. Istri yang ditalaq raj'i

Menurut Shafi'iyyah, Malikiyah dan Hanabilah, istri yang ditalak raj'i tidak wajib ibdad. ${ }^{43}$ Argument yang dibangun adalah karena wanita yang ditalaq raj'i masih terikat ikatan suami istri (zamjiyyah) dan tetap berlaku hukum istri. Oleh sebab itu masih boleh untuk berhias dan bersolek, ${ }^{44}$ bahkan Shafi'iyah menyatakan sunnah berhias jika rujuk masih dimungkinkan dan

\footnotetext{
${ }^{38}$ Muhammad bin Idris al-Shafi'i, Al-Um, (Maktabah Shamelah), jilid V, 230.

${ }^{39}$ Ibnu Rushd, Bidayat, Jilid II, hal 123. Dan Ibnu Nujaym, al-Babr al-Raiq, jilid IV, 163.

${ }^{40}$ Muhammad bin Idris al-Shafi'i, $A l-U m$, jilid V, 230.

${ }^{41} \mathrm{Abu}$ Umar Yusuf al-Namri al-Qurtubi, Al-Kafi, jilid II, 622.

${ }^{42}$ Malik bin Anas, Al-Mudawwanah, jilid II, 12.

${ }^{43}$ Abdullah Ibnu Qudamah, al-Mughni, jilid IX, 167., Malik bin Anas, AlMudawwanah, jilid II, 12., dan Abu Umar Yusuf al-Namri al-Qurtubi, Al-Kafi, jilid II,622.

${ }^{44}$ Abdullah bin Ahmad Ibnu Qudamah, al-Mughni, jilid IX, 167.
} 
menimbulkan kebaikan. Pendapat ini juga disampaikan Abu Thaur. ${ }^{45}$

\section{Tujuan Ihdad}

Tujuan dishariatkannya ibdad dilihat dari analisa beberapa definisi dan dasar hukum di atas dapat dirumuskan:

1. Agar para laki-laki tidak mendekati dan tergoda wanita yang sedang 'iddah.

2. Agar wanita yang sedang iddah tidak mendekati dan tergoda laki-laki.

Kedua hal ini oleh Ibnu Rushd disebut dengan sad aldzari'ab. ${ }^{46}$ Artinya menutup jalan keharaman. Jalan yang dimaksud adalah interaksi wanita 'iddah dengan laki-laki (dua tujuan di atas) dan berhias atau bersolek. Sedangkan keharamannya adalah pinangan (khitbah) dan pernikahan pada saat wanita dalam masa 'iddah. Oleh sebab itu dapat dikatakan bahwa illat hukum dishariatkannya ibdad adalah menjaga sikap wanita dari terjerumus dalam perkawinan pada masa 'iddah yang dilarang.

Oleh karena tujuan ibdad sebagaimana tersebut di atas, maka sangat wajar jika penekanan ulama dalam menulis fiqh ihdad pada dua hal:

1. Menanggalkan perhiasan atau bersolek.

2. Menghindarkan diri dari interaksi sosial.

Oleh karena itu segala hal yang mengarah pada dua hal tersebut dilarang pada saat ihdad. Menurut ulama', pakaian dan perhiasan yang tidak boleh digunakan pada masa iddah dan ibdad adalah pakaian yang dapat mempercantik diri (zinab) dan mendorong percepatan pernikahan baru. ${ }^{47}$

\section{Maqasid Ash-Shari'ah Sebagai Alasan Penetapan Hukum} Pengertian Maqasid Shariah

Maksud-maksud syari'at adalah tujuan yang menjadi target teks dan hukum-hukum partikular untuk direalisasikan dalam

${ }^{45}$ Muhammad al-Khatib al-Sharbini, al-Iqna' fi Hilli Alfadz. Abi Shuja', (Maktabah Shamelah), jilid II, 471.

${ }^{46}$ Ibnu Rushd, Bidayat al-Mujtahid, Jilid II, 124.

${ }^{47} \mathrm{Abu}$ Umar Yusuf al-Namri al-Qurtubi, Al-Kafi, jilid II, 623. 
dalam kehidupan manusia, baik berupa perintah, larangan dan mubah, untuk individu, keluarga, jamaah dan umat. ${ }^{48}$ Maksudmaksud syari'at ini bukanlah 'illat yang disebutkan oleh para ahli ushul fiqh dalam bab qiyas, dan didefinisikan dengan sifat yang jelas, tetap, serta sesuai dengan hukum.

Al-Shatiby menguraikan, bahwa Maqasid al-Shari'ah, ditinjau dari dua bagian. Menurutnya :

$$
\begin{aligned}
& \text { المقاصد التي ينظر قسمين : أحدهما يرجع إلى قصد الشارع والأخر يرجع إلى قصد المكلف المالف }
\end{aligned}
$$

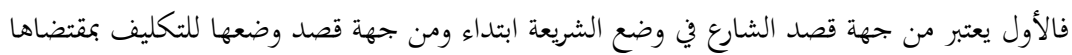

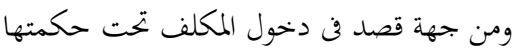

Untuk dapat memahami Maqasid al-Shariah atau tujuan syariah itu secara sempurna, maka terlebih dahulu paparkan beberapa unsur dari Maqasid Shariah, yaitu bakim, bukum, mabkum fih dan mabkum alaih. Dalam syariat Islam, tujuan syariat Islam (Maqasid al-Shari'ah al-Islam) lebih tinggi dan bersifat abadi, artinya tidak terbatas kepada bidang materil saja yang bersifat sementara, karena faktor-faktor individu, masyarakat dan kemanusiaan pada umumnya selalu diperhatikan dan dirangkaikan satu sama lain. Dengan hukum Islam, dimaksudkan agar kebaikan umat manusia dapat terwujud.

\section{Klasifikasi Hukum Syari'at}

Pemebebanan hukum syari'at melekat dengan maksudmaksudnya pada makhluk. Maksud-maksud syari'at tersebut dapat diklasifikasikan kepada tiga macam, yaitu: daruriyyat, bajiyyat, dan tabsiniyyat.

\section{Daruriyyat}

Adapun daruriyyat artinya sesuatu yang semestinya harus ada untuk menegakkan kemaslahatan, baik agama maupun dunia. Seandainya hal itu tidak ada, maka rusaklah kemaslahatan dunia tidak berjalan dengan baik kegiatan dunia tersebut. Dan dari aspek agama, tidak terlepas siksa Allah di akhirat dan berada dalam kerugian besar. ${ }^{49}$ Daruriyyat ini mencakup masalah

${ }^{48}$ Yusuf Al-Qardawi, Fiqh Maqasid Shari'ah, 17.

${ }^{49}$ Ibid., 324. 
dasar-dasar ibadah, adat kebiasaan dan mu'amalat. Daruriyyat berarti masalah pokok ibadah yang harus dilaksanakan untuk memelihara agama, seperti beriman, mengucap dua kalimat syahadah, mendirikan shalat, membayar zakat, berpuasa di bulan Ramadhan, berhaji dan lain sebagainya, yang termasuk dalam hal-hal yang wajib dikerjakan. Daruriyyat juga berkenaan dengan adat kebiasaan, meliputi halhal yang dapat memelihara jiwa dan akal, yaitu makan, minum, sandang dan papan, dan lain sebagainya. Daruriyyat dalam hal mu'amalat adalah memelihara keturunan dan harta, termasuk juga memelihara jiwa dan akal. ${ }^{50}$

2. Haijiyyat

Adapun bajjiyyat, artinya sesuatu yang sangat diperlukan untuk menghilangkan kesulitan yang dapat membawa kepada hilangnya sesuatu yang dibutuhkan, tetapi tidak sampai merusak kemaslahatan umum.

Hajjiyyat ini berlaku baik pada berbagai macam ibadah, adat kebiasan, mu'amalat dan pada kriminal atau jinayat. Pada ibadah, misalnya dispensasi ringan karena sakit atau musafir, boleh meninggalkan puasa, menjamak shalat dan meng-qasarnya. Pada masalah adat kebiasaan, misalnya dibolehkannya berburu, makan makanan halal dan bergizi, dan lain sebagainya. Sedangkan pada mu'amalah dan jinayah adalah seperti melaksanakan transaksi qirad $\}$, jual beli salam dan lain-lain. Pada jinayah, seperti hukum sumpah atas pembunuhan berdarah (qasamab) dan kewajiban membayar diyat pembunuhan kepada keluarga terbunuh. ${ }^{51}$

3. Tabsiniyyat

Adapun makna tabsiniyyat, adalah mengambil sesuatu yang paling baik dari yang baik menurut adat kebiasaan dan menjauhi hal-hal yang jelek yang tidak diteriima oleh akal yang sehat. Atau dalam arti lain, tabsiniyyat adalah apa yang terhimpun dalam batasan akhlak yang mulia, ${ }^{52}$ Baik dalam masalah ibadah, seperti

50 Ibid., 325.

${ }^{51}$ Ibid., 327.

52Ibid., 327. 
menghilangkan najis, melakukan berbagai macam cara dalam bersuci, maupun dalam adat kebiasaan, seperti adab makan dan minum. Begitu juga dalam hal mu'amalat, seperti dilarang jual beli najis dan dicegah membunuh orang merdeka dengan sebab dia membunuh budak pada masalah jinayat atau kriminal. ${ }^{53}$

\section{Metode Penetapan Maqasid}

Muhammad Tahir ibn 'Ashur dalam bukunya berjudul Maqasid Shariah Islamiyyah, mengatakan: ada tiga cara menetapkan Maqasid Shari'ah, yaitu:

1. Dengan cara istiqra' (pengambilan beberapa sampel) bagi syari'at yang diterapkan. Cara ini adalah yang terbaik dalam mendapatkan Maqasid Shari'ah, dan terbagi ke dalam dua macam. Yang paling baik dari dua macam itu adalah memeriksa sampel hukum-hukum yang telah makruf dengan 'illat, lalu memeriksa 'illat tersebut pada proses pengambilan hukum dengan 'illatitu. Dengan demikian dimungkinkan dipahami maksud syari'at. ${ }^{54}$

2. Metode mengkaji dalil ayat-ayat al-Quran yang jelas dilalabnya, sehingga dengan demikian kecil kemungkinan maksud suatu ayat diragukan lahir maknanya atau bukan seperti lahir penggunaan kaedah bahasa Arab. ${ }^{55}$

3. Metode melihat hadith mutawatir, baik mutawatir ma'nawi atau mutawatir 'amali. Mutawatir maknawi adalah mutawatir yang diperoleh dari pengamatan perilaku para sahabat yang mengamalkan semuanya apa yang dilihat pada diri Nabi Saw. Dengan demikian dapat menghasilkan ilmu yang meyakinkan pada masalah agama. Sedangkan mutawatir 'amali adalah apa yang diperoleh oleh seorang sahabat dari perbuatan Nabi yang berulang-ulang, sehingga dia berkesimpulan bahwa begitulah maksud syari'at itu. ${ }^{56}$

\section{Tujuan Maqasid al-Shari'ah}

${ }^{53}$ Ibid., 327.

${ }^{54}$ Muhammad Tahir ibn 'Ashur, Maqasid Shariah Islamiyah, (Tunisia: Dar asSalam, 2006), 17.

${ }^{55}$ Ibid., 19.

${ }^{56}$ Ibid., 19. 
Ada beberapa tujuan Maqasid Al-Shari'ah, antara lain, adalah: 1. Menuju fiqh baru (Madrasah Moderat; dengan menggabungkan teks-teks partikular dan maksud-maksud global). Fiqh baru ini dibangun oleh madrasah moderat yang tidak melupakan teksteks partikular dari al-Quran dan Sunnah, tetapi dalam satu waktu juga tidak memisahkannya dari maksud-maksud global. Bahkan teks-teks partikular tersebut dipahami dalam bingkai maksudmaksud global. Mengembalikan furu' kepada usul, partikular kepada global, mutashbbihat kepada mubkamat, juga memegang teguh ijma' ulama dan menjadikan jalan orang-orang mukmin tidak boleh dilanggar. Manhajinilah yang ditempuh para ulama penggagas dan penerus teori Maqasid Shariah, seperti al-Juwaini, al-Gazali, Rashid Rida, Al-Shatiby, Ibn 'Ashur, Qaradawi dan lain sebagainya. Madrasah ini yang dipercaya, dijadikan sebagai gambaran yang benar tentang hakekat Islam, membantah kebatilan orang-orang yang memusuhinya, serta berbaik sangka kepada Allah dan Rasul-Nya dalam semua hukum-Nya. ${ }^{57}$ Fiqh yang dihasilkan oleh mereka, bisa menjelaskan tujuan, menerangi jalan, menyinari pandangan menuju manhaj Islam yang lurus. Dan kita tidak ditimpa oleh kegelapan dalam memahami agama dan dunia. ${ }^{58}$

2. Menjauhi fiqh madrasah "Zahiriyyah Baru" dan menjauhi Madrasah Penganulir Teks-teks partikulir di dalam Al-Quran dan Sunnah. Madrasah "Zabiriyah Baru”, lebih bergantung pada teks-teks partikular, memahaminya dengan pemahaman literal dan jauh dari maksud-maksud syariat yang ada di belakangnya. Bahkan mereka berpendapat, bahwa Allah bisa saja memerintahkan kita dengan hal yang Dia larang kepada kita, serta melarang kita dengan hal-hal yang Dia perintahkan kepada kita. Dan bahkan Dia bisa memerintahkan kita syirik dan melarang tauhid. Di antara ciri lainnya adalah keras dan menyulitkan, sombong terhadap pendapat mereka serta tidak mau menerima pendapat orang lain yang berbeda dengannya. ${ }^{59}$

${ }^{57}$ Yusuf Al-Qardawi, Figh Maqasid Shari'ah , 40.

${ }^{58}$ Ibid., 9.

${ }^{59}$ Ibid., 50-52. 
Di sisi lain, ada madrasah yang sangat berlawanan dengan madrasah di atas. Madrasah ini mengklaim bahwa mereka lebih bergantung kepada maksud-maksud syariat dan ruh agama dengan menganulir teks-teks partikulir dalam al-Quran dan Sunnah. Mereka memandang bahwa agama adalah substansi bukan simbol, isi bukan bentuk, memegang mutashabihat dan menolak mubkamat. ${ }^{60}$ Ini di antara tujuan dari pembelajaran dan pemahaman kita tentang Maqasid Shariah dalam ushul fiqh yang dapat ditemukan.

\section{'Iddah bagi Wanita Karir melalui Pendekatan Maqasid ash- Shari'ah}

Menarik kiranya definisi yang diungkapkan Hanafiyah dan Shafi'iyyah tentang fungsi 'iddah, tetapi redaksi Shafi'iyyah lebih jelas. Ulama' Hanafiyyah menyatakan, bahwa fungsi 'iddah adalah untuk menghabiskan sesuatu yang masih tersisa akibat dari pernikahan. Sesuatu yang masih tersisa akibat pernikahan adalah kemungkinan kehamilan (rahim) dan hak-hak seperti rujuk, nafkah, dan lainnya. Sedangkan Shafi'iyyah secara jelas mengatakan, fungsi iddah ada tiga, yakni untuk mengetahui kosongnya rahim, pengabdian pada Allah SWT. dan bela sungkawa atas kematian suami. Beberapa definisi tersebut memunculkan pertanyaan mendasar mengenai fungsi iddah yang menjadi illat hukum diwajibkannya 'iddah. Apakah 'illat hukum 'iddah adalah untuk mengetahui isi rahim atau kekosongan rahim, ataukah pengabdian pada Allah, ataukah belasungkawa, ataukah ketiganya merupakan kesatuan yang menjadi illat hukum iddah. Hal ini karena redaksi yang digunakan dalam rumusan definisi 'iddah menggunakan kata sambung huruf 'ataf berupa "ؤو" yang identik berfungsi untuk takbyir (pemenuhan salah salah satu).

Mengenai 'illat 'iddah, Musa al-Hijawi dalam karyanya al-Iqna' fi billi alfadri Abu Shuja' menyatakan bahwa 'illat 'iddah yang lebih dominan (al-mughallab fib) adalah t'abbudi. ${ }^{61}$ Istilah ta'abbudi identik

${ }^{60}$ Ibid., 38.

${ }^{61}$ Musa al-Hijawi, al-Iqna' fi hilli alfadzi Abu Shuja', (Beirut: Dar al-Fikr, 1990), jilid II, 125. 
dengan ibadah yang menghasilkan pahala. Jika demikian maka seharusnya lebih adil jika laki-laki diberi peluang memperoleh pahala melalui iddah. Begitu juga wanita yang pada saat putus perkawinannya masih belum pernah berhubungan badan dengan suami juga diberi peluang dengan memperoleh pahala melalui 'iddah, namun ternyata fiqih dan ijma' tidak mengharuskan 'iddah bagi wanita ini. ${ }^{2}$

Jika fungsi ‘iddah merupakan ungkapan bela sungkawa (tafajju) semata, seharusnya akan menjadi adil jika laki-laki juga dibebani iddah. Agaknya stressing iillat iddah lebih pada mengetahui kosongnya rahim. Terlebih menurut Shaykh Zayn alDin al-Malibari dan Shaykh Abu Yahya Zakariya al-Ansari serta ulama' Shafi'iyyah lainnya, tujuan disyariatkannya 'iddah adalah untuk menjaga kemurnian nasab agar terhindar dari kekacauan nasab. ${ }^{63}$ Imam Nawawi menyatakan bahwa tujuan disyariatkannya iddah adalah untuk mengetahui isi rahim atau kosongnya rahim, oleh karenanya iddah bagi wanita hamil adalah sampai masa kelahiran. ${ }^{64}$ Begitu juga ketentuan bagi wanita yang pada saat putus perkawinannya masih belum pernah berhubungan badan dengan suami (غير المدخول بها), menurut ijma' tidak berlaku 'iddah bagi wanita ini. ${ }^{65}$ Hal ini menunjukkan bahwa illat iddah adalah untuk mengetahui isi rahim.

Agaknya memang terdapat tiga unsur pertimbangan dalam ketetapan 'iddah, yakni pertimbangan religiusitas (ta'abbudi), unsur etika moral (tafajju) untuk memperlihatkan kesedihan atas hilangnya nikmat pernikahan, dan unsur penyelamatan nasab (bara'ah al-rahim). Ketiganya menjadi satu kesatuan fungsi 'iddah, namun argumentasi di atas lebih menunjukkan bahwa illat 'iddah adalah ta'abbudi. Oleh sebab itu, definisi 'iddah yang sesuai pada masa kontemporer ini adalah definisi menurut ulama' Shafi'iyyah yang mendefinisikan iddah dengan: "Masa penantian yang digunakan

${ }^{62}$ Ibnu Rushd, Bidayat, Jilid II, 66.

${ }^{63}$ Zayn al-Din al-Malibari, Fath al-Mu'in, hal. 37, Abu Yahya Zakariya al-Ansari, Fath al-Wabab, jilid II, 179.

${ }^{64}$ Muhyi al-Din bin Sharaf al-Nawawi, al-Majmu', jilid 18, 127.

${ }^{65} \mathrm{Ibnu}$ Rushd, Bidayat, Jilid II, 66. 
wanita (janda) untuk mengetahui kosongnya rahim, pengabdian pada Allah dan bela sungkeawa atas kematian suami' ${ }^{106}$

Jika melihat tujuan keluar rumah yang dilakukan wanita karir adalah tidak sekedar mencari nafkah, tetapi lebih dari itu, yakni meningkatkan taraf hidup dari sisi finansial dan karir, maka hal ini merupakan suatu keniscayaan yang harus dilakukan wanita tersebut. Terlebih ketika finansial keluarga sudah menjadi tidak jelas sumbernya akibat perceraian maupun kematian suami, karena pada awalnya tulang punggung keluarga berada pada tanggung jawab suami sehingga kebutuhan keluarga dipenuhi suami. Bahkan jika wanita 'iddah tidak berkarir dan bekerja, malah akan terjerumus pada kondisi yang menyulitkan dari sisi finansial dalam memenuhi kebutuhan keluarga yang kemudian akan berdampak pada kehancuran keluarga pasca perceraian atau kematian suami.

Dengan demikian, tujuan wanita karir keluar rumah untuk melakukan aktifitas karirnya dan pekerjaannya untuk memenuhi kebutuhan keluarga, tergolong hajat yang sangat mendesak ( الحاجة (الماسة الشديدة yang dapat menempati posisi darurat. Permasalahan ini dapat menggunakan argumentasi dengan kaidah

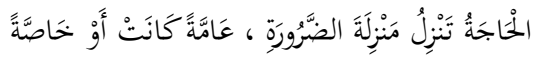

"Hajat (kebutuhan) dapat menempati posisi darurat baik tergolong hajat umum maupun khusus"

Ketika dinyatakan sebagai hajat yang menempati darurat, maka d \}arurat yang ada harus dihilangkan sekalipun dengan menerjang keharaman atau larangan. Hal ini sesuai dengan kaidah:

$$
\begin{aligned}
& \text { "Keadaan darurat memperbolehkan (menerjang) perkara yang } \\
& \text { dilarang” }
\end{aligned}
$$

\section{Ihdad bagi Wanita Karir}

${ }^{66}$ Zayn al-Din al-Malibari, Fath al-Mu'in, hal. 37, Abu Yahya Zakariya al-Ansari, Fath al-Wahab, jilid II, 179. 
Konsepsi ibdad adalah melarang wanita 'iddah untuk berhias. Telah dijelaskan bahwa tujuan disyariatkannya ibdad (larangan berhias) adalah:

1. Agar para laki-laki tidak mendekati dan tergoda wanita yang sedang 'iddah.

2. Agar wanita yang sedang iddah tidak mendekati dan tergoda laki-laki.

Kedua hal ini oleh Ibnu Rushd disebut dengan sad aldzari'ah. ${ }^{67}$ Artinya menutup jalan keharaman. Jalan yang dimaksud adalah interaksi wanita 'iddah dengan laki-laki (dua tujuan di atas) dan berhias atau bersolek. Sedangkan keharamannya adalah pinangan (kbitbah) dan pernikahan pada saat wanita dalam masa 'iddah. Karenanya 'illat hukum disyariatkannya ibdad adalah menjaga sikap wanita dari terjerumus dalam perkawinan pada masa iddah yang dilarang. Jadi berhias merupakan sarana interaksi (wasilah atau dzara') yang dimungkinkan wanita 'iddah akan terjerumus dalam pernikahan pada masa iddahnya. Oleh karenanya terdapat rumusan dabit.

"Setiap sesuatu yang tidak tergolong perbiasan (mempercantik. diri) tidak masalah digunakan bagi wanita ('iddah dan ibdad) karena dapat mencegah pernikahan dan sesuatu yang semakna dengan pernikahan". 68

Di sisi lain, wanita karir tertuntut keadaan untuk menjaga relasi sosial dengan selalu berpenampilan menarik dengan berhias diri sehingga ia dapat menyelesaikan pekerjaannya tanpa harus dijauhi rekan kerja atau bahkan banyak yang menghindari bekerjasama dengannya akibat penampilannya yang tidak menarik (memalukan). Hal ini kemudian dapat berdampak pada hancurnya pekerjaan dan karir pribadi si wanita serta kestabilan tempat kerja karena wanita karir tersebut tidak dapat menyelesaikan pekerjaannya dengan baik dan tepat waktu. Terlebih jika jenis pekerjaan atau karir wanita ini berimplikasi pada kemaslahatan atau kemaadharatan publik, seperti presiden, anggota legislatif (DPRMPR), dan lainnya. Hal ini akan menimbulkan dampak bahaya bagi

${ }^{67}$ Ibnu Rushd, Bidayat, Jilid II, 124.

${ }^{68} \mathrm{Abu}$ Umar Yusuf al-Namri al-Qurtubi, Al-Kafi, jilid II, 623. 
publik. Oleh karena itu, berpenampilan menarik bagi wanita karir menjadi penting dilakukan untuk menjaga karir dan pekerjaannya.

Dapat dirumuskan, bahwa tujuan wanita karir berpenampilan menarik adalah untuk menjaga karir dan pekerjaannya agar tetap menjadi sumber pemenuhan kebutuhan hidup. Maka berpenampilan menarik merupakan wasilah karir dan pekerjaan. Jika dilihat dari subtansi berpenampilan menarik memiliki tujuan untuk menjaga karir dan pekerjaan agar tetap menjadi sumber pemenuhan kebutuhan hidup, maka berhias tergolong hajat yang mendesak untuk memenuhi kebutuhan hidup yang jika tidak dipenuhi akan jatuh pada kehancuran karir dan pekerjaan yang berimplikasi pada kehancuran ekonomi. Oleh karenanya, tepat jika kacamata hajat yang menempati posisi darurat digunakan untuk menetapkan hukum, bahwa wanita karir boleh untuk berhias (meninggalkan ibdad) ketika melakukan aktifitas karir atau pekerjaannya.

\section{Kesimpulan}

Pertimbangan yang dapat merubah hukum 'iddah dan ibdad ketika berbenturan dengan masalah wanita karir adalah pertimbangan hajat dan darurat mengingat efektifitas hajat dan darurat sehingga penyelesaian hukum 'iddah dan ibdad bagi wanita karir dapat dikatakan lebih aplikatif, efektif dan humanis untuk era kekinian dengan pertimbangan hajat dan darurat.

Iddah bagi wanita karir tetap harus dilakukan mengingat illat hukum 'iddah lebih bersifat ta'abbudi. Namun dalam hal konsekwensi hukum 'iddah, berupa larangan keluar rumah, hal ini tidak dapat diberlakukan bagi wanita karir mengingat karir dan pekerjaan wanita karir bersifat kebutuhan, karena merupakan sumber pemenuhan kebutuhan hidup yang tergolong bajat mendesak untuk melestarikan hidup yang jika tidak dipenuhi akan jatuh pada kehancuran ekonomi (kemiskinan).

Mengingat $i b d a d$ bagi wanita yang sedang ' $i d d a h$ sebatas sad aldzara'i, artinya berhias dianggap perantara yang dapat menimbulkan dorongan berupa tujuan pernikahan pada masa 'iddah, yang jika tujuan utama ihdad dapat dieliminir dengan argumentasi hajat dan darurat, maka hukum perantara mengikuti 
hukum tujuan. Artinya, bahwa berhias merupakan hajat bagi wanita karir yang boleh dilakukan pada masa 'iddah karena bertujuan menjaga karir dan pekerjaan, sehingga ibdad tidak dapat diberlakukan bagi wanita karir.

\section{Daftar Pustaka}

Fuad Abdul Baqi, Nayl al-Awtar, Maktabah Shamelah.

Abu Daud, Sunan Abu Daud, Maktabah Shamelah.

Abdurrahman bin Muhammad al-'Asimi, Hashiyah al-Rand alMurabba' Sharb Zad al-Mustaqna', Maktabah Shamelah.

Abu Yahya Zakariya al-Ansari, Ghayat al-Wusul fi Sharb Lub alWusul, Surabaya, al-Hidayah, tt.

--, Fath al-Wahab bi Sharb Manbaj al-Tullab, Beirut, Dar al-Kutub al-'Alamiyyah, tt.

-,Al-Ashbah wa al-Nazair, Beirut, Dar al-Kutub al'Alamiyyah, 1980.

Shalih bin Muhammad al-Asmari, Majmu'ab al-Fawa'id alBabiyah 'ala mandhumat al-Qawa'id al-Babiyyah, Surabaya, al-Hidayah, 2000.

Al-Bukhari, Sahih al-Bukhari, Maktabah Shamelah.

Syah Waliyullah al-Dihlawiy, Hujjah Allah al-Balighah, Beirut, Dar Ihya`al-Ulum, tt.

Zayn al-Din Ibnu Nujaym al-Hanafi, al-Bahr al-Raiq Sharb Kan₹u al-Daqaiq, Maktabah Shamelah.

Musa al-Hijawi, al-Iqna' fi billi alfadri Abu Shuja', Beirut: Dar alFikr, 1990.

Ala'uddin al-Kasani, Bada'i' al-Shana'I fi Tartibi al-Shara'i, Maktabah Shamelah.

Zayn al-Din al-Malibari, Fath al-Mu'in, Beirut, Dar al-Fikr, tt. Abu Hasan al-Mawardi, Al-Hawi al-Kabir, Maktabah Shamelah. Ahmad bin Ghanim bin Salim al-Nafrawi, al-Fawakih al-Diwani 'ala Risalati Ibn Abi Zayd al-Qayrawani, Maktabah Shamelah.

Al-Nasa'i, Sunan al-Nasa'i, Maktabah Shamelah.

Al-Nawawi al-Jawi, Nibayat al-Zayn, Maktabah Shamelah.

Muhyi al-Din bin Sharaf al-Nawawi, al-Majmu' Sharb alMuhazzab, Maktaba Shamelah. 
Abu Umar Yusuf al-Namri al-Qurtubi, Al-Kafi fi Fiqh Abli alMadinah, Riyadl, Maktabah Riyadl al-Hadithah, 1980.

Abd al-Rahman bin Nasir al-Sa'adi, Sharb Nazm al-Qawa'id alFiqhiyyah, Maktabah Shamelah.

Ali al-Sabuni, Rawa'I al-Bayan fi Tafsiri aayat al-Abkam, Beirut, Dar al-Fikr, tt.

Muhammad bin Idris al-Shafi'i, Al-Um, Maktabah Shamelah.

Muhammad al-Khatib al-Sharbini, al-Iqna' fi Hilli Alfadr. Abi Shuja, Maktabah Shamelah.

Taj al-Din Abd al-Wahhab al-Subki, Al-Ashbah wa al-Nazair, Beirut: Dar al-Kutub al-'Alamiyyah, 1991.

Abu Bakar al-Suyuti, Al-Ashbah wa al-Naza’ir, Beirut, Dar alKutub al-'Alamiyyah, tt.

Wahbah al-Zuhaily, al-Fiqh al-Islamiy Wa Adillatubu, Damaskus, Dar al-Fikr, 1996.

Simone de Beauvoir, The Second Sex Book One: Facts and Myths, Surabaya, Pustaka Promethea, 2003.

Ibnu al-Qayyim, I'lam al-Muwaqqi'in, Maktabah Shamelah, tt.

Malik Ibnu Anas, Al-Mudawwanah al-Kubra, Beirut, Dar al-Kutub al-Alamiyyah, tt.

--------, al-Muwatta', Maktabah Shamelah.

Abdullah bin Ahmad Ibnu Qudamah, al-Mughni, Maktabah Shamelah.

Ibnu Rushd, Bidayat al-Mujtahid Wa Nihayat al-Muqtasid, Beirut, Dar al-Fikr, 1998.

Tapi Omas Ihromi, Wanita Bekerja dan Masalah-Masalabnya, Dinamika Wanita Indonesia, Jakarta, Pusat Pengembangan Sumberdaya Wanita, 1990.

Ahmad Kafi, al-Hajah al-Shar'iyyah Hududuba wa Qawa'iduba, Beirut, Dar al-Kutub al-Alamiyyah, 2004.

A. M. Sahal Mahfudz, dalam Pengantar Husein Muhammad, Figh Perempuan Refleksi Kiai atas Wacana Agama dan Gender, Yogyakarta, Lkis, 2009.

Anton M Moeliono, (Penyunting Penyelia), Kamus Besar Bahasa Indonesia, Jakarta, Departemen Pendidikan dan Kebudayaan RI, 1989. 